Fuell, K. K., B. J. Guyer, D. Kann, A. L. Molthan, and N. Elmer, 2016: Next generation satellite RGB dust imagery leads to operational changes at NWS Alburquerque. J. Operational Meteor., 4 (6), 75-91, doi: http://dx.doi.org/10.15191/nwajom. 2016.0406.

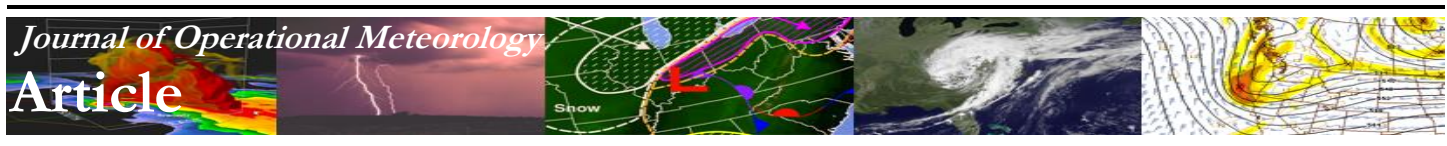

\title{
Next Generation Satellite RGB Dust Imagery Leads to Operational Changes at NWS Albuquerque
}

\author{
KEVIN K. FUELL \\ University of Alabama in Huntsville/Earth System Science Center, Huntsville, Alabama \\ BRIAN J. GUYER and DEIRDRE KANN \\ NOAA/National Weather Servce, Albuquerque, New Mexico \\ ANDREW L. MOLTHAN \\ NASA Marshall Space Flight Center/Earth Science Office, Huntsville, Alabama \\ NICHOLAS ELMER \\ University of Alabama in Huntsville/Department of Atmosopheric Science, Huntsville, Alabama
}

(Manuscript received 8 July 2015; review completed 9 February 2016)

\begin{abstract}
The National Aeronautics and Space Administration/Short-term Prediction Research and Transition (SPoRT) Center has been providing unique, multispectral red-green-blue (RGB) composite imagery to operational forecasters since 2004. More recently, SPoRT has used the European Organization for the Exploitation of Meteorological Satellites "best practices" standards for RGB composites to transition a wide array of imagery for multiple uses. A "Dust" RGB product has been made available for evaluation at the National Weather Service (NWS) in Albuquerque, New Mexico (ABQ), since 2012. Several cases have occurred where forecasters were able to isolate dust plume locations for mesoscale and synoptic events during daytime and nighttime conditions. This type of imagery is a large change from the single channel imagery typically used by operational forecast staff and, therefore, can be a challenge to interpret. This paper focuses on the integration of such new imagery into operational use as well as the benefits assessed by NWS ABQ over several documented events. The primary benefits include improvements in short-term forecasts of ceiling conditions for the aviation community as well as improved decision support services and communication to the general public regarding blowing dust.
\end{abstract}

\section{Introduction}

The detection of blowing dust events, particularly at night, has been a significant challenge for current Geostationary Operational Environmental Satellite (GOES) imagery and algorithms. Typically, during the daytime, dust and thin cloud features have a similar appearance in visible imagery. At night, current GOES infrared imagery does not easily identify low-level features such as blowing dust, except in extreme cases of thick dust plumes of large areal extent. Even in these extreme dust events, cloud features in the scene can often obscure the dust and complicate interpretation of the imagery. Operational forecasters in the southwestern United States have developed new aviation forecast policies and procedures for dust hazards based on improved capabilities from National Oceanic and Atmospheric Administration (NOAA) and National Aeronautics and Space Administration (NASA) polar-orbiting imagers that demonstrate future geostationary capabilities. Since 2010, forecasters at the National Weather Service (NWS) in Albuquerque, New Mexico (ABQ), have transitioned toward using multi-spectral satellite imagery from polar-orbiting instruments for dust detection and analysis. Operational changes have been developed as a result of this transition to improve support services for the aviation and ground transportation communities.

Currently scheduled for launch in late 2016, the GOES-R series represents the next generation of geostationary satellite capabilities for the continental 
United States, featuring an Advanced Baseline Imager (ABI, Schmit et al. 2005) that will improve the spatial, spectral, and temporal resolution of satellite observations used in weather analysis and forecasting applications. Similarly, the next generation of NOAA's polarorbiting missions - the Joint Polar Satellite System (JPSS) - is being developed with the first launch of JPSS-1 scheduled for early 2017 . The JPSS platform will provide continuity for observations currently available on the Suomi National Polar Orbiting Partnership (S-NPP) satellite. In preparation for these missions, NOAA has established the Satellite Proving Grounds to prepare operational forecasters for day-one readiness in the use of GOES-R (GOES-R Proving Ground, Goodman et al. 2012) and JPSS (JPSS Proving Ground, Goldberg et al. 2013). As a participant in NOAA's Satellite Proving Grounds, the NASA Shortterm Prediction Research and Transition (SPoRT) Center (Jedlovec 2013) partners with NOAA/NWS Weather Forecast Offices (WFOs) throughout the country to provide training on and assessment of products and techniques that will become available in the GOES-R and JPSS eras. Additional spectral bands provided by the ABI will lead to new applications of geostationary-based, multispectral imagery. In preparation, SPoRT has presented current forecasters with imagery and products from the Moderate Resolution Imaging Spectroradiometer (MODIS) aboard NASA's polar-orbiting Terra and Aqua satellites, and the Visible Infrared Imaging Radiometer Suite (VIIRS, Hillger et al. 2013) aboard S-NPP. The greater number of spectral bands on MODIS and VIIRS compared to GOES-13 and GOES-15 allows for demonstration of applications from the future GOES-R and JPSS series imagers.

Earlier work regarding remote sensing of airborne dust examined daytime infrared channel differencing techniques (Ackerman 1989). Enhanced daytime dust detection over water via composites and multispectral algorithms were developed using MODIS and the Advanced Very High Resolution Radiometer (Lee 1989; Miller 2003). Multispectral products also have been generated from the Spinning Enhanced Visible and Infrared Imager (SEVIRI) instrument on the geostationary Meteosat Second Generation (MSG) satellite and operationally implemented to address a number of forecast challenges for both daytime and nighttime applications. Referred to as "RGB Imagery" or "RGB Products," brightness temperatures or paired band differences are used to set the red, green, and blue intensities of each pixel in the final image, resulting in a false-color composite specifically designed to highlight features of interest by distinct colors. The European Organization for the Exploitation of Meteorological Satellites (EUMETSAT) has established a "best practices" set of guidelines for various RGB products (EUMETSAT 2009), such as the RGB Air Mass product evaluated by Zavodsky et al. (2013), and other multi-spectral imagery products used to highlight various atmospheric features (e.g., low clouds and fog, intense convection, etc.), or to create a natural or true color view of the earth's surface. Recently, these best practices also have been extended to the Japanese Himawari-8/Advanced Himawari Imager (AHI) following declaration of its operational status in July 2015 (Meteorological Satellite Center 2015), allowing forecasters to use AHI to apply similar RGB imagery products to the western Pacific region as were initially developed from SEVIRI. Herein, discussion focuses on derivation and application of the EUMETSAT Dust RGB product. Other dust products via the aforementioned research were not operationally implemented at NWS ABQ at the time, but also would likely be supportive of addressing these forecast challenges.

The application of the EUMETSAT Dust RGB product to the detection and analysis of hazardous blowing dust events by forecasters at NWS ABQ focused particularly on synoptic and mesoscale events impacting ground and air transportation industries. Figure 1 shows the range of complex topography over New Mexico, the location of two major interstate travel corridors (I-25 and I-40), and several NWS Terminal Aerodrome Forecast (TAF) points (NWS 2015b). The NWS is responsible for disseminating timely and accurate aviation weather forecast information, particularly ceiling and visibility conditions, to the users of the National Aerospace System. Prior to the availability of the Dust RGB product, forecasters identified blowing dust by utilizing legacy GOES single-channel visible and infrared satellite imagery, a sparse network of automated surface observing system reports, first-hand ground observations via the NWS SKYWARN® spotter network, and broadcast or social media resources. This information was then coordinated with customers and partners through the issuance of short-term forecasts, special weather statements, updates to the National Digital Forecast Database (NDFD, Glahn and Ruth 2003), and telephone briefings for more significant dust events. Persistent, longterm drought conditions over New Mexico from 2011 to 2014 helped to increase the frequency and intensity of blowing dust events across many areas of the state 


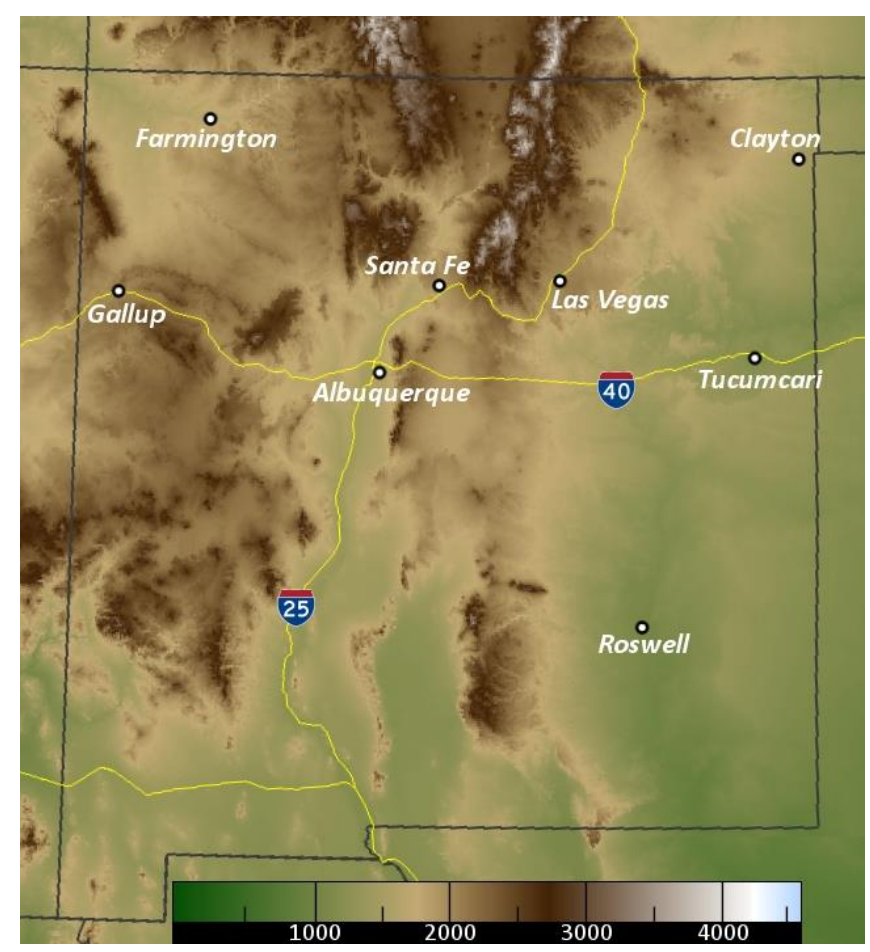

Figure 1. Topographical map of NM (meters). TAF sites in the NWS ABQ county warning area are labeled with white circles, including Clayton in northeastern New Mexico. Click image for an external version; this applies to all figures hereafter.

(Fig. 2), particularly for 2012 and 2013 at Tucumcari and Roswell. The inclusion of the Dust RGB product into operations at NWS ABQ enhanced the forecaster's ability to analyze blowing dust on a range of scales for both daytime and nighttime events. This imagery also facilitated new opportunities for visual communication of the spatial extent of these hazardous events to NWS ABQ users. Use of the Dust RGB product also encouraged the development of satellite interpretation skills and analysis methodologies, which enhanced user readiness training and operational application requirements prior to the launch of GOES-R.

Analysis herein focuses on the application of the Dust RGB product to blowing dust events that occurred on 14 April 2012, 26 March 2012, and 11 March 2014 within or bordering New Mexico. In particular, it focuses on the changes in communications and services at NWS ABQ that address the unique challenges associated with blowing dust events, while highlighting future capabilities of GOES-R. Section 2 describes the Dust RGB product creation and basic interpretation of the resulting composite colors. Section 3 has detailed analyses of the two cases outlining aviation applications for multi-source synoptic-scale and single-source mesoscale events - in addition to a third case that outlines the improved decision support services to the general public related to ground transportation hazards. Section 4 provides a summary of the impact to operations of the Dust RGB product at NWS ABQ.

\section{Data and methods}

The Dust RGB product is produced through a false color combination of paired channel differences and single channel imagery (Table 1), using the $8.7-\mu \mathrm{m}$, $10.8-\mu \mathrm{m}$ (sometimes referred to as $11 \mu \mathrm{m}$ ), and $12-\mu \mathrm{m}$ brightness temperatures (BTs). These channels lie in the $8-10-\mu \mathrm{m}$ and $10-12-\mu \mathrm{m}$ regions of the spectrum, where dust and aerosols display strong spectral variation and the atmosphere is virtually transparent. Consequently, dust aerosols display greater absorption at $10.8 \mu \mathrm{m}$ than at $12 \mu \mathrm{m}$, whereas the opposite is true for thin clouds such as cirrus (Ackerman 1997). For this reason, the Dust RGB product incorporates the 12 $\mu \mathrm{m}-10.8 \mu \mathrm{m}$ BT difference in the red componentwhich is physically related to optical thickness of clouds and dust - to differentiate between dust (positive difference) and thin cloud (negative difference). To discriminate between airborne dust and underlying desert surfaces, and for some discrimination of particle phase, the $10.8 \mu \mathrm{m}-8.7 \mu \mathrm{m}$ BT difference is used in the green component. A desert surface is characterized by a lower emissivity at $8.7 \mu \mathrm{m}$ than at $10.8 \mu \mathrm{m}$ (Ogawa and Schmugge 2004; Moreira 2011), while dust and clouds exhibit nearly equal emissivity at these wavelengths. As a result, a desert background has a large positive $10.8 \mu \mathrm{m}-8.7 \mu \mathrm{m}$ BT difference, and dust and clouds have a small, positive difference. Use of the $10.8 \mu \mathrm{m}-8.7 \mu \mathrm{m}$ BT difference for particle phase inference is preferred more than the well-known $10.8 \mu \mathrm{m}-0.9 \mu \mathrm{m}$ BT difference used to identify low clouds and fog (Eyre et al. 1984; Ellrod 1995) because the $8.7-\mu \mathrm{m}$ channel does not suffer from daytime contamination of solar reflectance at the $3.9-\mu \mathrm{m}$ wavelength. This allows for continuous use of the Dust RGB product, though use of the $10.8 \mu \mathrm{m}-8.7 \mu \mathrm{m}$ BT difference provides reduced sensitivity to particle phase and less color variation between low (liquid phase) and high (ice phase) clouds. Finally, the single channel 10.8- $\mu \mathrm{m}$ BT is included as a component of the Dust RGB product to provide information about skin and cloud-top temperature.

To enhance dust features in the Dust RGB product, the $12 \mu \mathrm{m}-10.8 \mu \mathrm{m}$ difference, the $10.8 \mu \mathrm{m}-8.7$ $\mu \mathrm{m}$ BT difference, and the $10.8-\mu \mathrm{m} \mathrm{BT}$ are constrained 


\section{Frequency of Dust and Haze Observations at NWS ABQ TAF Sites}

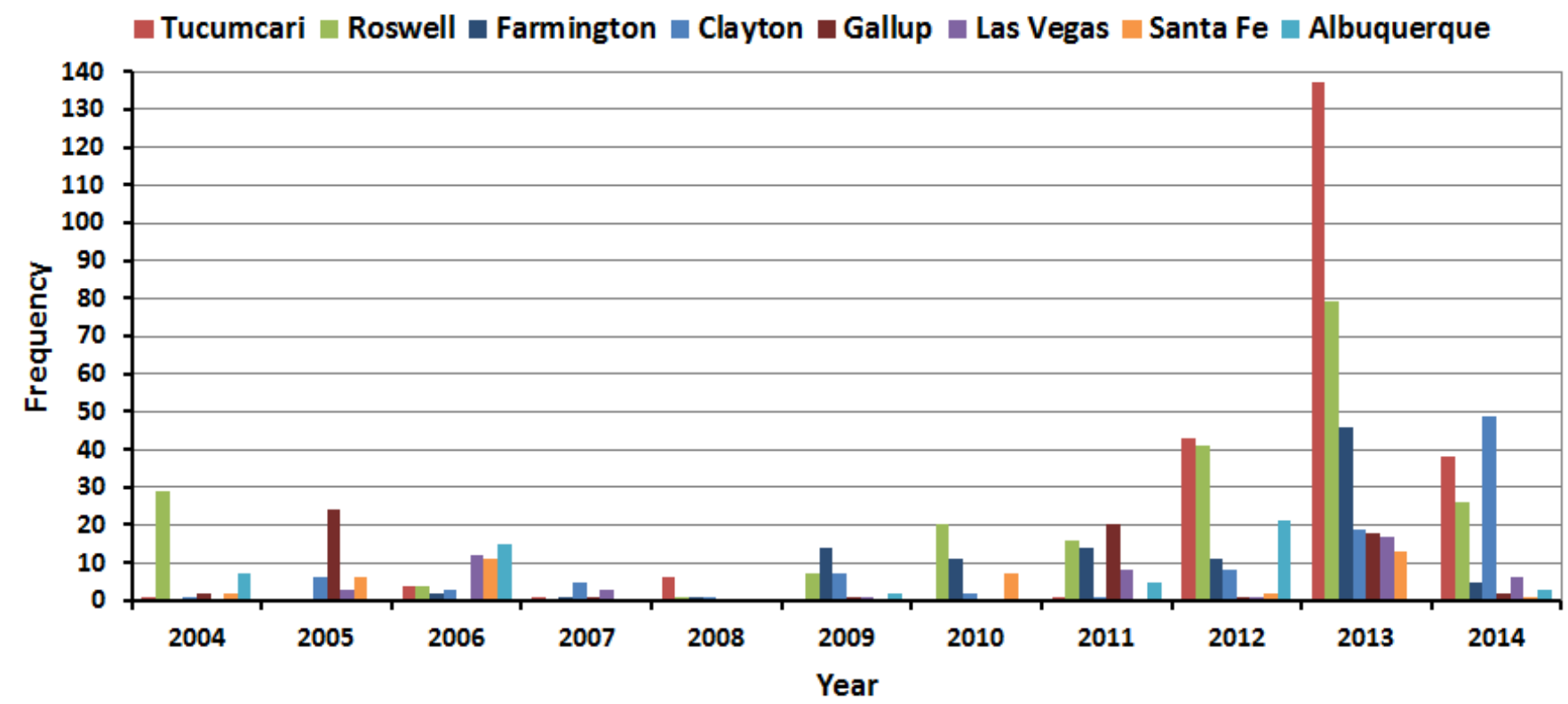

Figure 2. Frequencies of blowing dust and haze observations from 4 January 2004 through 1 June 2014 at the eight sites depicted in Fig. 1. The observations at each site were filtered for visibilities $\leq 4.8 \mathrm{~km}(3 \mathrm{mi})$, measurable precipitation, and temperatures $\leq 0^{\circ} \mathrm{C}\left(32^{\circ} \mathrm{F}\right)$.

Table 1. Spectral bands used to create the Dust RGB product as stated in the EUMETSAT "best pactices" RGB imagery documentation (EUMETSAT 2009), along with their physical interpretation and associated thresholds used to determine the final intensity of coloration for individual pixels. Analogous channels from MODIS and VIIRS are used to create the RGB.

\begin{tabular}{|c|c|c|c|c|c|}
\hline Color & Wavelengths & Physical & Min & Max & Gamma \\
\hline $\mathrm{R}$ & $12.0 \mu \mathrm{m}-10.8 \mu \mathrm{m}$ & Optical Thickness & $-4 \mathrm{~K}$ & $+2 \mathrm{~K}$ & 1.0 \\
\hline $\mathrm{G}$ & $10.8 \mu \mathrm{m}-8.7 \mu \mathrm{m}$ & Particle Phase & $0 \mathrm{~K}$ & $15 \mathrm{~K}$ & 2.5 \\
\hline $\mathrm{B}$ & $10.8 \mu \mathrm{m}$ & Temperature & $261 \mathrm{~K}$ & $289 \mathrm{~K}$ & \\
\hline
\end{tabular}

to a predefined range when the color shading is assigned. The color intensity of the red, green, and blue shading is based upon the following equation:

$$
(\mathrm{R}, \mathrm{G}, \mathrm{B})=255\left[\left(\left(T_{B} \text { or } \Delta \mathrm{T}_{B}\right)-M I N\right) /(M A X-M I N)\right]^{\left(1 / y_{R, G, B}\right)}
$$

where $\left(T_{B}, \Delta T_{B}\right)$ represents either a single band BT or a BT difference among two bands, min and max represent the range of values used to constrain the individual color components, and $\gamma_{R, G, B}$ is the gamma enhancement for each color input when $\gamma_{R, G, B} \neq 1$. The ranges and gamma values used for image enhancement for each color input are shown in Table 1. The red, green, and blue intensities are then combined to create the final 24-bit RGB image. Note that although the individual components of the RGB are derived from quantitative BT values, the resulting composite is a qualitative image that combines the individual color intensities to form a single color that represents the combination of physical attributes of the sensed object or surface. Therefore, other quantitative observations of visibility and ceiling are useful where available to confirm the potential hazards depicted in the qualitative imagery.

Some minor limitations existed regarding the Dust RGB product display as well as the individual sensor retrievals from MODIS and VIIRS. In NWS operations at the time of the cases, the Advanced Weather Interactive Processing System (AWIPS) was limited to 254 colors, which requires the 24-bit images be colorquantized to a 254-color palette, resulting in a slight degradation of image quality. However, this did not impair the use of the products in operational assessments. The upgrade to AWIPS II completed in 2015 supports a full 24-bit display of future products. Two other technical limitations involve the use of LowEarth Orbit (LEO) instruments. First, slight hardware differences exist between the two MODIS instruments aboard Terra and Aqua due to their construction and age. Second, there are differences in the spectral bands and characteristics of the MODIS and VIIRS sensors. These sensor differences can cause the color of an 
RGB feature to vary depending on the specific instrument used to create the RGB product, which can lead to inconsistent interpretation and comparison of products from multiple sensors. In addition, BTs appear to cool in the single channel infrared imagery at larger viewing angles due to an effect known as limb-cooling (Lienesch and Wark 1967; Goldberg et al. 2001; Joyce et al. 2001), which can adversely impact the interpretation of RGB products away from the nadir view. Ongoing research focuses on addressing sensor differences and limb-cooling effects among the various instruments to improve consistency (Elmer 2015); however, the presence of sensor differences and limbcooling in the Dust RGB product did not preclude the use of the imagery in operational applications as shown in the 26 March 2012 case in section 3.

\section{a. Dust $R G B$ product interpretation}

During the daytime, the Dust RGB product highlights areas of lofted dust as bright magenta to pink shading - resulting from large amounts of red and blue pixel coloration - but little to no green (Table 2). Recall from the product recipe (Table 1) that the red component is a proxy for optical thickness and the blue component relates to the skin temperature. Dust is less absorptive at the $12.0-\mu \mathrm{m}$ wavelength than at the 10.8- $\mu \mathrm{m}$ wavelength (Ackerman 1997). Thus, for dust plumes with low-to-moderate optical thickness, the $12.0-\mu \mathrm{m}$ wavelength is influenced by the underlying surface emissions, and it will therefore have a warmer brightness temperature than the $10.8-\mu \mathrm{m}$ wavelength. This results in a large red contribution. However, for very optically thick dust plumes, the dust plume will absorb a large component of both wavelengths, resulting in a small brightness temperature difference and a low red contribution. At the point of origin, the dust plume is lower in the atmosphere as it originates from ground level, and it will typically be warmer than most cloud features. Therefore, dust also receives a large blue contribution resulting in magenta for the dust image pixel in daytime, which is the focus of cases in this paper. Only very physically thick dust plumes at low levels will appear in a non-magenta color (typically bright purple), both during the day and night. The concentration and height of the daytime dust object in the RGB cannot be determined via the shades of magenta. However, at night variations in the resulting Dust RGB imagery colors can provide a general height delineation where low-, mid-, and high-level dust are bright purple, purple, and pink, respectively (Schipper and Nietosvaara 2009).
Table 2. Representative color intensity values for various features within the Dust RGB product, including dust aloft and other cloud features described within the text or shown in subsequent figures.

\begin{tabular}{|l|c|c|c|}
\hline Feature & $\begin{array}{l}\text { Red } \\
\text { Pixel } \\
\text { Value }\end{array}$ & $\begin{array}{l}\text { Green } \\
\text { Pixel } \\
\text { Value }\end{array}$ & $\begin{array}{l}\text { Blue } \\
\text { Pixel } \\
\text { Value }\end{array}$ \\
\hline Dust aloft & 235 & 50 & 175 \\
\hline High, thick cloud & 150 & 5 & 5 \\
\hline High, thin cloud & 5 & 1 & 5 \\
\hline Mid, thick cloud & 140 & 75 & 15 \\
\hline Mid, thin cloud & 15 & 90 & 20 \\
\hline $\begin{array}{l}\text { Low, thick cloud } \\
\text { (warm climate) }\end{array}$ & 170 & 130 & 190 \\
\hline $\begin{array}{l}\text { Low, thick cloud } \\
\text { (cold climate) }\end{array}$ & 170 & 130 & 50 \\
\hline
\end{tabular}

In addition to the primary purpose of monitoring dust plumes, many cloud and surface features can be distinguished in the Dust RGB product. Thin, upperlevel clouds (e.g., cirrus too optically thin in visible channels) tend to be dark blue to black (low amounts of blue and other color contributions). Thick, mid- to high-level clouds will have low blue intensity, and they are shades of red to tan in color, respectively. For midlevel, thick clouds with super-cooled water particles, a greater contribution of green occurs than for ice clouds, which combines with the red to result in tan shades. Because of the aforementioned differences in emissivity, thin, high clouds typically have a very low green contribution, often similar to the green contribution in dust, while desert surfaces have a large green contribution. Desert surfaces also typically have high contributions from the red and blue color components; however, the strong diurnal variation over deserts causes the surface coloring to vary, especially due to the use of the 10.8- $\mu \mathrm{m}$ band in each RGB component. For cloudy regions, a green edge is often seen around midlevel clouds, indicating relatively cold, thin clouds of mostly super-cooled liquid water. Over desert regions such as those in the United States Southwest, a unique case of green-colored cirrus clouds occurs when there is an underlying desert surface due to the low emissivity of desert soil in the $8.7-\mu \mathrm{m}$ wavelength. The appearance of these green cirrus clouds over the desert may seem strange, as black-colored cirrus 
clouds will be directly adjacent where the underlying surface changes to non-desert.

At night, thin dust plumes vary in color depending on their height. High, thin dust appears magenta while more purple is seen in low, thin dust plumes (Schipper and Nietosvaara 2009). To assist with the relatively complex interpretation of the various colors, Dust RGB product training was provided to NWS ABQ through a series of short lessons conducted both remotely and during onsite visits over several dust seasons. Application of the product was also supported through the use of Dust RGB "Quick Guide" reference sheets within the operations area, and peer-to-peer interactions from product advocates within the office who had more experience.

\section{b. Product dissemination}

Data used operationally by NWS ABQ during the dust events in this paper were provided by NASA SPoRT in near-real-time through the use of UNIDATA Local Data Management (LDM) software used by NWS regions and local WFOs. The MODIS and VIIRS data were originally obtained by Direct Broadcast (DB) sites and made available by the Space Science and Engineering Center (SSEC) at the University of Wisconsin. In order to minimize latency of the product to forecasters, SPoRT obtained data via SSEC's Abstract Data Distribution Environment servers, processed multiple bands locally to create the Dust RGB imagery, quantized the imagery to an 8bit/254-color palette for AWIPS, and disseminated the single RGB imagery file using the LDM software. With the DB access and use of the LDM, the MODIS and VIIRS Dust RGB imagery products arrived approximately $45-60 \mathrm{~min}$ after their valid time. The WFO received a Dust RGB image 30-40 min later than an equivalent $G O E S$ image, which is provided to NWS ABQ about 15-20 min after the time of observation. Compared to GOES imagery, only a limited number of MODIS and VIIRS images are available per day over the area of interest, which prevents animation of the Dust RGB product as would typically be done with GOES single-channel imagery. With combined use of MODIS and VIIRS, approximately four Dust RGB imagery products were available during both daytime and nighttime (a total of eight per $24 \mathrm{~h}$ ); however, the valid time of the overpasses varied daily due to the 16day repeat cycle for the Terra, Aqua, and S-NPP satellites. Aqua (MODIS) and S-NPP (VIIRS) equatorial crossing times are centered near 0130 and 1330 local time (or 0830 and 2030 UTC for NWS ABQ) while Terra (MODIS) is centered near 1030 and 2230 local time (or 1730 and 0530 UTC for NWS ABQ); however, the overpass time can vary by roughly an hour on either side of the center point. For a given point, this overpass pattern leaves two large gaps in LEO coverage from roughly 0300 to 0900 and 1500 to 2100 local time (or 1000-1600 and 2200-0400 UTC for NWS ABQ) - during which the forecaster will not have access to a Dust RGB product.

\section{Analysis and discussion}

Use of the Dust RGB product at NWS ABQ has been documented by forecasters in at least 18 different cases over the 2012-2014 time period. The cases have ranged from those featuring small, local source regions of dust, to large-scale wind events with widespread impacts spanning both daytime and nighttime periods. Three examples are presented here to highlight the range of Dust RGB product applications and user confidence derived from these documented cases, which eventually led to changes at NWS ABQ in the operational procedures used to communicate dust storm forecasts and current hazards to public and aviation communities.

\section{a. Mesoscale orographic dust, 26 March 2012: TAF ceiling designations}

A localized blowing dust case with aviation impacts occurred on 26 March 2012 at the Farmington, New Mexico (KFMN), airport in extreme northwestern New Mexico (Fig. 1). A broad upper-level trough was positioned over the West Coast, with southwest flow aloft over New Mexico. A short-wave trough ahead of the broad upper-level trough was forecast to move over the Four Corners area during the daytime. East of the New Mexico central mountain chain, some mid- and high-level moisture was evident in soundings and on standard satellite imagery. A wind advisory was issued for the extreme northeastern corner of the state, with the criteria for sustained winds of $13.9 \mathrm{~m} \mathrm{~s}^{-1}$ $(27 \mathrm{kt})$. This advisory also included the possibility of blowing dust. The morning soundings from NWS ABQ indicated that ridge top (3000 m) wind speeds approached $15.4 \mathrm{~m} \mathrm{~s}^{-1}$ (30 kt), and upwind at Flagstaff, Arizona, wind speeds at the same level exceeded 25.7 $\mathrm{m} \mathrm{s}^{-1}(50 \mathrm{kt})$. Model soundings indicated that winds aloft would be increasing during the daytime across much of New Mexico, including the Four Corners area. However, across western New Mexico, gusty 
southwest winds were expected to remain below advisory criteria with steady veering after 1800 UTC. The 1200 UTC TAF for KFMN specified winds increasing to $7.7 \mathrm{~m} \mathrm{~s}^{-1}$ (15 kt) by 1400 UTC and gusting to $12.9 \mathrm{~m} \mathrm{~s}^{-1}(25 \mathrm{kt})$ by 1800 UTC with clear skies. By $1600 \mathrm{UTC}$, southerly winds at $7.2 \mathrm{~m} \mathrm{~s}^{-1}$ (14 kt) gusting to $11.3 \mathrm{~m} \mathrm{~s}^{-1}$ (22 kt) were reported at KFMN (Table 3 ). The aviation forecaster initially used this observation when preparing the 1800 UTC TAFs, increasing the magnitudes of both the sustained speeds and gusts for the afternoon winds while maintaining clear skies. When the 1700 UTC observation for KFMN posted, a visibility restriction of $8 \mathrm{~km}(5 \mathrm{mi})$ was reported with haze and blowing dust. Additionally, three ceilings were reported, with the lowest at $1158 \mathrm{~m}(3800 \mathrm{ft})$, supporting visual flight rules (VFR) but approaching the marginal VFR (MVFR) category (Table 4). This unanticipated ceiling prompted a quick check of visible (Fig. 3) and infrared satellite imagery, which appeared to indicate clear skies and led the aviation forecaster to question the validity of the in situ observation. Although wave clouds are common in the Farmington area, they would generally occur at a higher level. A more careful check of animated visible imagery hinted at a small-scale feature over the area and the 1800 UTC TAF for KFMN was subsequently issued maintaining a visibility of $8 \mathrm{~km}(5 \mathrm{mi})$ and a

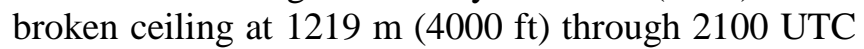
in the prevailing conditions, though the forecaster had considerable uncertainty.

One hour after TAF issuance, the 1900 UTC observation for KFMN indicated the lowest broken ceiling had decreased to $975 \mathrm{~m}(3200 \mathrm{ft})$ while visibility restrictions improved from 8 to $16 \mathrm{~km}$ (5 to $10 \mathrm{mi}$ ). The 1819 UTC Dust RGB product from Terra MODIS (Fig. 4a) was received around 1910 UTC and it clearly indicated a narrow, localized dust plume over KFMN from a previously unknown source region in higher terrain to the southwest. The application of the Dust RGB product provided an immediate validation of the observation, and efficiently illustrated the areal extent impacted by elevated blowing dust.

At 2000 UTC impacts at KFMN continued with a

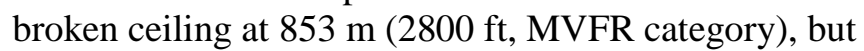
no surface visibility restrictions were reported. Given the confirmation by the MODIS RGB images of blowing dust as the source of the observed ceiling and continued decreasing ceiling height, the KFMN TAF was amended just prior to 2100 UTC to extend the MVFR ceiling until 2300 UTC. A subsequent Aqua MODIS Dust RGB product valid at 2001 UTC_-but received

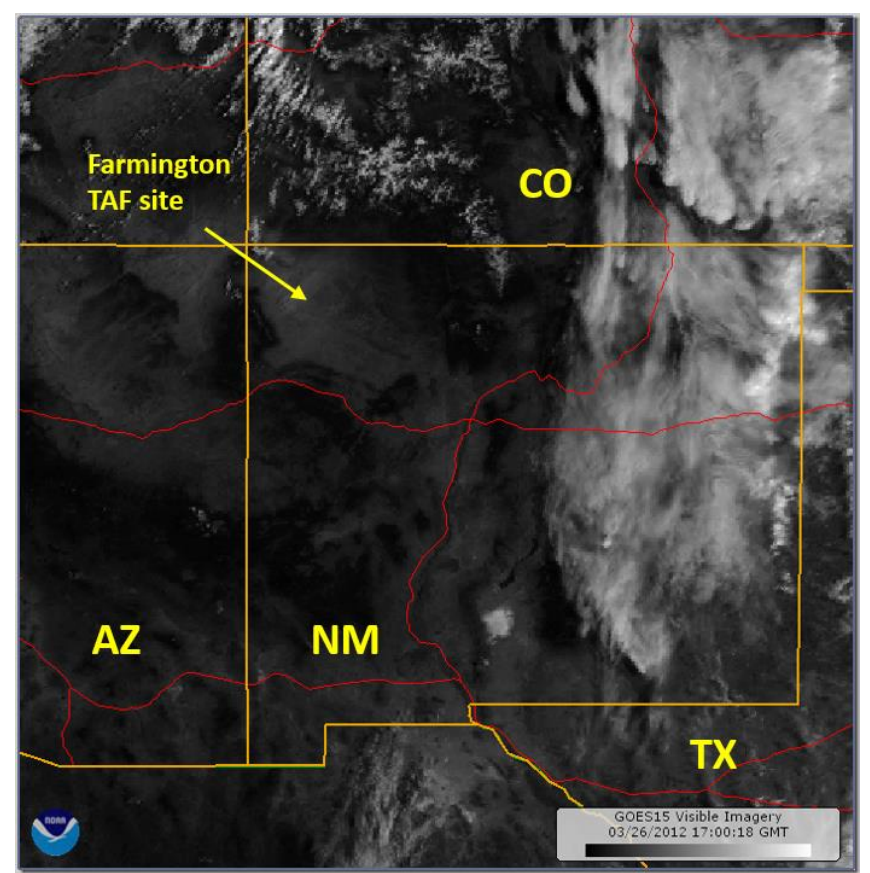

Figure 3. GOES visible imagery valid at 1700 UTC 26 March 2012 over NM, with major highways in red and state borders in tan. The yellow arrow points to the approximate location of the Farmington, NM, TAF site for NWS ABQ.

around 2100 UTC (Fig. 4b) - indicated that the primary dust plume had moved downstream of the source region, and a separate dust plume developed in southern Colorado. The 2001 UTC Dust RGB product showed that the source region upwind of KFMN was no longer producing dense, elevated dust (i.e., lack of magenta). Thus, the forecaster could anticipate that the TAF would not likely need a further amendment to the ceiling, and that the ceiling conditions were going to improve shortly. Note that the Dust RGB imagery in Fig. 4 has similar coloring of dust, clouds, and land surfaces even though they are from differing platforms and no bias adjustment or limb-cooling corrections were being made at this time.

With drought conditions persisting throughout the region, the formation of a small-scale dust plume was noted during several other, similar synoptic events in the spring and fall of 2012. Although anticipation and confidence improved at KFMN, these cases served as the impetus for a discussion regarding how best to handle ceilings caused by elevated blowing dust that were not accompanied by surface visibility obscurations. At the time of this case it was unclear if it was procedurally appropriate to include ceilings due to dust and not clouds in the official TAF because current NWS directives only defined ceilings as related to clouds. Following coordination with the NWS aviation 
Table 3. Observed conditions at Farmington, NM (KFMN), for 1600-2200 UTC 26 March 2012. Observations marked with an asterisk (*) are MVFR and the rest are VFR. "BKN" and "OVC" represent "Broken" and "Overcast" sky cover conditions, respectively. Multiply mi by 1.61 for $\mathrm{km}$; multiply $\mathrm{ft}$ by 0.305 for $\mathrm{m}$.

\begin{tabular}{|c|c|c|c|c|}
\hline Time (UTC) & $\begin{array}{c}\text { Wind Dir. / Speed / Gust } \\
\text { (Degrees, kt, kt) }\end{array}$ & Visibility (mi) & Obscuration & $\begin{array}{c}\text { Ceilings \& Height } \\
\text { (ft AGL) }\end{array}$ \\
\hline 1553 & $180 / 14 / 22$ & 10 & & Clear \\
\hline $1653^{*}$ & $220 / 12 / 20$ & 5 & Haze / Blowing Dust & BKN $3800 \mathrm{ft}, \mathrm{BKN} 4800 \mathrm{ft}$, OVC $7000 \mathrm{ft}$ \\
\hline $1753^{*}$ & $260 / 18 / 26$ & 5 & Haze & BKN $3400 \mathrm{ft}, \mathrm{OVC} 4200 \mathrm{ft}$ \\
\hline 1853 & $290 / 10 / 19$ & 10 & & BKN $3200 \mathrm{ft}, \mathrm{OVC} 4200 \mathrm{ft}$ \\
\hline $2050^{*}$ & $280 / 13 / 21$ & 10 & & OVC $3000 \mathrm{ft}$ \\
\hline $2053^{*}$ & $300 / 11 / 21$ & 10 & & OVC $3000 \mathrm{ft}$ \\
\hline 2153 & $280 / 12 / 20$ & 10 & & Clear \\
\hline
\end{tabular}

Table 4. Aviation flight category definitions used by NWS forecasters. The qualifier between ceiling and visibility favors the lower category in mixed cases. For example, if a ceiling is VFR and the visibility is IFR, then the flight conditions are IFR. Conversions to km and mi are as in Table 3.

\begin{tabular}{|c|c|c|c|}
\hline \multicolumn{5}{|c|}{ Aviation Flight Category Definitions } \\
\hline Category & Ceiling (ft) & Qualifier & Visibility (mi) \\
\hline Visual Flight Rules (VFR) & $>3000$ & and & $>5$ \\
\hline Marginal Visual Flight Rules (MVFR) & 1000 to 3000 & and/or & 3 to 5 \\
\hline Instrument Flight Rules (IFR) & 500 to $<1000$ & and/or & 1 to $<3$ \\
\hline Low Instrument Flight Rules (LIFR) & $<500$ & and/or & $<1$ \\
\hline
\end{tabular}

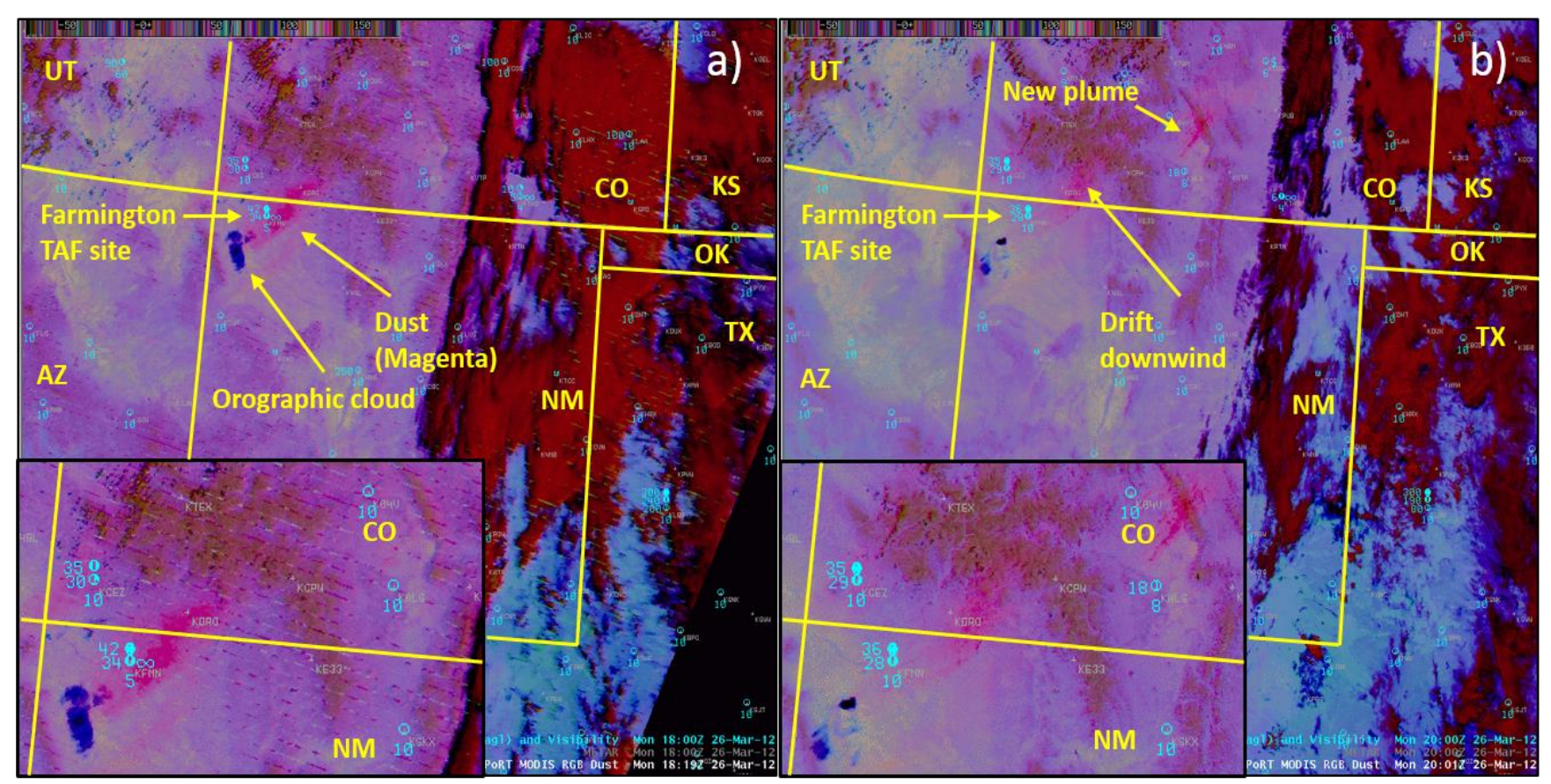

Figure 4. Dust RGB product at (a) 1819 UTC and (b) 2001 UTC on 26 March 2012. Data via MODIS and displayed in AWIPS-D2D. Images are centered over NM with the Farmington TAF site labeled. Aviation station observations in light blue showing cloud cover fraction (circle) visibility (below circle, SM) and cloud ceiling height (hundreds of $\mathrm{ft}$ ). Insets of each panel provide greater detail in the area of the Farmington TAF site.

program at a regional level, it was determined to be appropriate to include ceilings due to elevated dust in TAFs, with details differentiating areas of dust from areas of clouds included in the aviation portion of the area forecast discussion.

\section{b. Large-scale dust storm, 14 April 2012: daytime and nighttime impacts}

The 14 April 2012 synoptic-scale case highlights the utility of the Dust RGB product in the operational forecast environment, particularly related to enhanced 
situational awareness, aviation products and services for Roswell, New Mexico (KROW), and analysis of blowing dust at night. A powerful jet stream moved over New Mexico on 14 April 2012 in association with an upper-level low pressure over the Great Basin. A surface trough deepened along the Front Range of the Rocky Mountains in response to this upper-level forcing, resulting in strong to damaging southwest winds over much of New Mexico. NWS ABQ issued a high wind warning for large areas of central and eastern New Mexico, following the criteria of sustained winds at or above $15.9 \mathrm{~m} \mathrm{~s}^{-1}(31 \mathrm{kt})$ and/or gusts at or above $29.8 \mathrm{~m} \mathrm{~s}^{-1}(58 \mathrm{kt})$. The combination of high winds and persistent severe to exceptional drought conditions (Fig. 5) were expected to increase the likelihood for areas of blowing dust, particularly downwind of source regions such as the Chihuahuan Desert and White Sands National Monument. Impacts to public and transportation communities as a result of the blowing dust were highlighted within the high wind warning product and also the weather grid element of the NDFD.
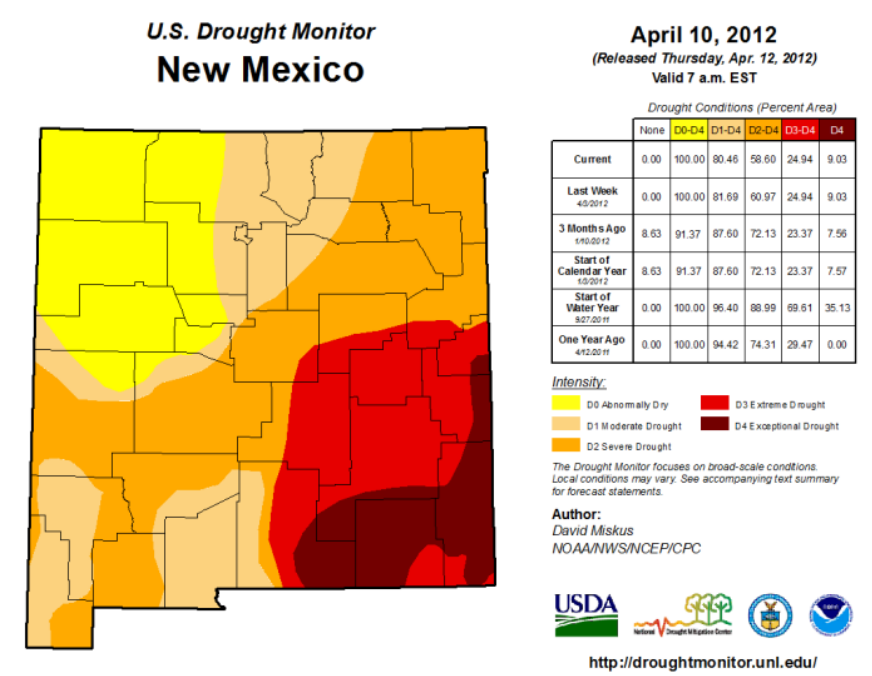

Figure 5. United States Drought Monitor for NM valid 10 April 2012 (droughtmonitor.unl.edu).

At 1710 UTC, the MODIS 1-km True Color imagery (not shown) indicated developing dust plumes over extreme northwestern Chihuahua, Mexico. As the upper-level storm shifted east and surface winds increased over the area, the 2033 UTC MODIS 1-km True Color and Dust RGB products showed several large dust plumes expanding over northern Mexico and much of south-central and eastern New Mexico (Fig. 6). The dust plumes were oriented near and immediately downwind of active source regions, but identification of the plumes was difficult against the underlying dry land surface feature in the True Color RGB image. However, the Dust RGB product provided a greater amount of detail on the spatial extent of blowing dust over the entire region. Several notable features are easily identified on the Dust RGB product, including the well-defined, extensive dust plume (magenta) emanating from a large source region over south-central New Mexico, dust through broken cloud cover within central New Mexico (yellow circle), and smaller source regions (yellow arrows) over eastern New Mexico and western Texas. The ability of the Dust RGB product to capture these more subtle areas of dust over the traditional suite of satellite products made the product particularly useful to the forecasters in improving the detection and monitoring of dust plumes.

Southwest winds continued to strengthen throughout the daytime ahead of a strong cold frontal boundary approaching from the west. The 2035 UTC observation at Sierra Blanca Regional Airport verified that visibilities had fallen to $4.0 \mathrm{~km}(2.5 \mathrm{mi})$ within the main axis of the dust plume as it crossed through south-central New Mexico. Forecasters later utilized the 2033 UTC Dust RGB product (arriving 2130 UTC) and developed a graphical web forecast, or "Graphicast," highlighting the expected evolution of the large-scale dust plume (Fig. 7). This was the first known illustration of how the Dust RGB product could be applied to the short-term forecast environment in the United States and supplement the existing suite of hazard forecast products. Forecaster confidence increased even further that the evolving dust plume would later impact aviation terminals at both Tucumcari (KTCC) and KROW as the strong cold front moved in from the west. The 1800 UTC TAF at KROW indicated VFR conditions for the entire 24-h forecast cycle. At $1951 \mathrm{UTC}$, visibility reductions to $12.9 \mathrm{~km}(8 \mathrm{mi})$ at KROW were reported and these conditions continued through 2326 UTC, or for about 3.5 $\mathrm{h}$. While the forecaster was developing the 0000 UTC TAF cycle, the visibility at KROW reduced to $4.0 \mathrm{~km}$ $(2.5 \mathrm{mi})$ with a ceiling of $853 \mathrm{~m}(2800 \mathrm{ft})$. The 0000 UTC TAF issued at 2341 UTC forecasted a prevailing visibility of $8 \mathrm{~km}(5 \mathrm{mi})$ with a ceiling of $1067 \mathrm{~m}$ $(3500 \mathrm{ft})$ through $0300 \mathrm{UTC}$. The combination of the surface observations, the improved depiction from the Dust RGB product, and the synoptic conditions, collectively supported forecaster confidence to include a temporary fluctuation in the meteorological conditions in the KROW TAF down to $3.2 \mathrm{~km}$ ( $2 \mathrm{mi}$; IFR, 


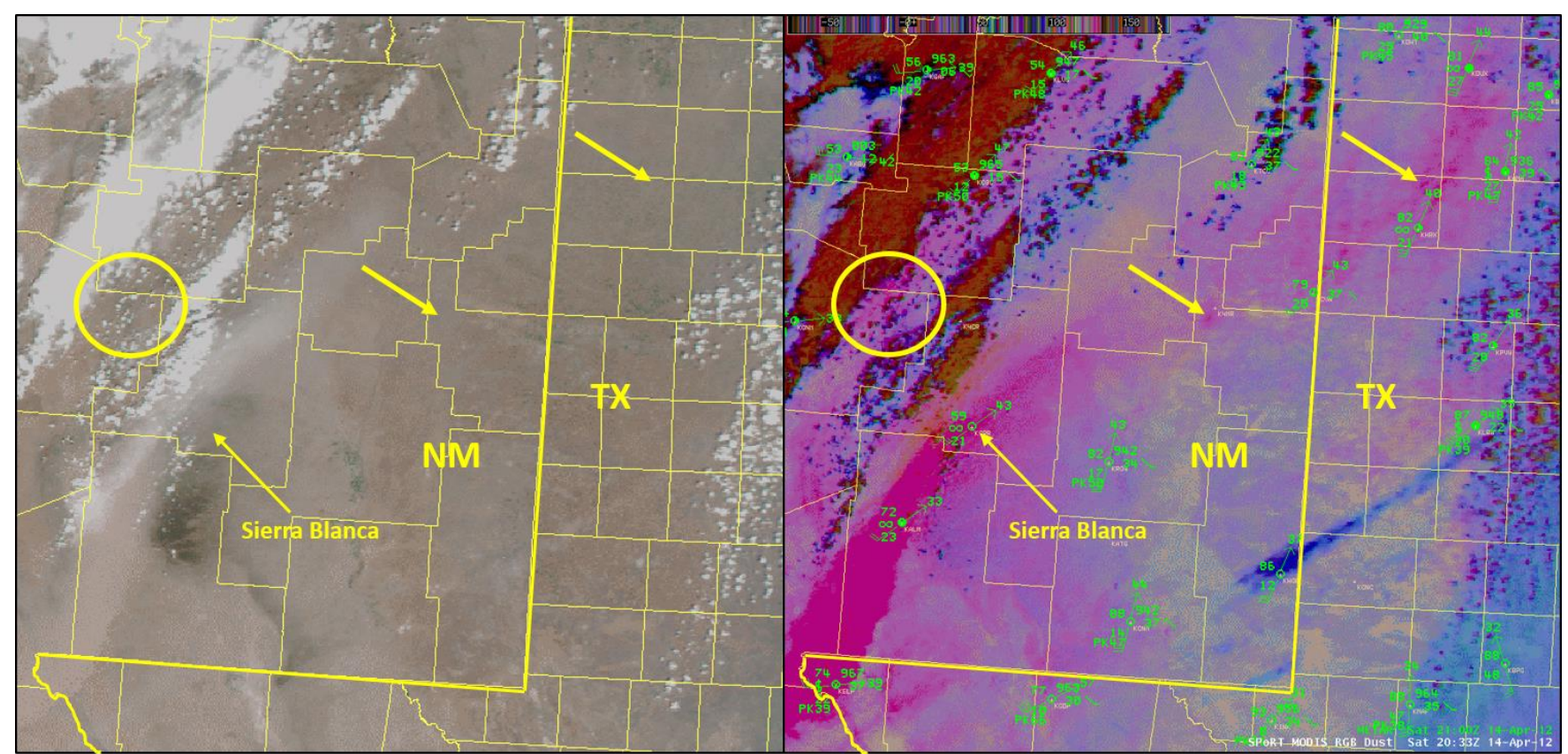

Figure 6. MODIS True Color RGB (left) and Dust RGB (right) products valid 2033 UTC 14 April 2012 over southeastern NM and western TX. Annotations are made in each image to illustrate enhancements in dust appearance and contrast between the True Color and Dust RGB imagery depictions.

\section{BLOWING DUST}

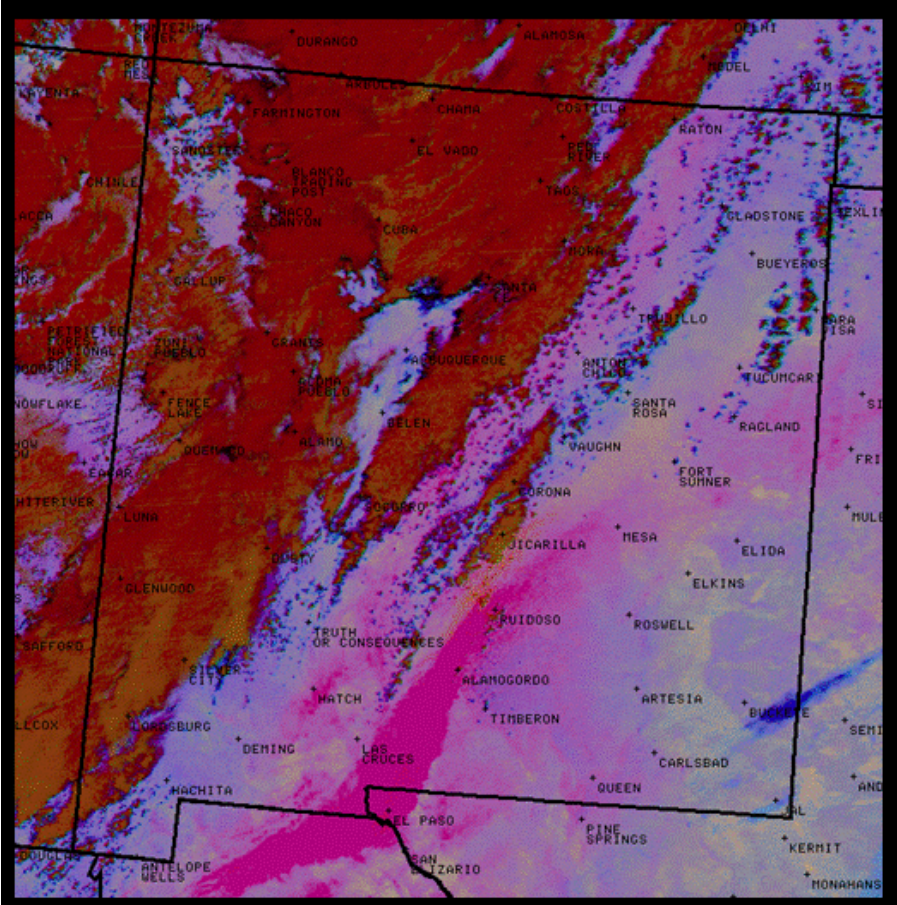

Dust from Mexico and southern New Mexico, as well as sand from White Sands National Monument, is blowing north-northeast. This is shown in the hot pink areas on the image to the left. Though there are likely areas of blowing dust to the west, clouds (shown in red and orange) is obscuring the satellite's view.

Visibilities will be reduced below one mile from Ruidoso, to Mesa, to Fort Sumner, to Clovis and Portales.

As the wind direction changes to the west later this afternoon, the dust will have a greater impact from Dunken to Roswell.

Dust RGB MODIS Satellite Imagery at 233pm. Courtesy of NASA SPoRT.

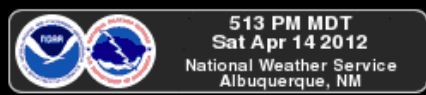

Figure 7. Graphicast produced by WFO ABQ forecasters and delivered to the public on 14 April 2012 after analysis of the Dust RGB product valid at 2033 UTC. 
see Table 4), with a ceiling of $762 \mathrm{~m}(2500 \mathrm{ft})$ and blowing dust between 0000 and 0200 UTC. By 0251 UTC, the visibility and ceiling restrictions reported by the site improved to VFR.

The impacts of the blowing dust at KROW shifted farther east as the cold frontal boundary continued to progress into west Texas through the evening of 14 April 2012. As mentioned above, because the Dust RGB product is derived from longwave infrared channels, it remains effective during daytime and nighttime events. The area of blowing dust over eastern New Mexico became more widespread along and behind the frontal boundary over West Texas during the evening as indicated by the MODIS Dust RGB product at 0417 UTC (Fig. 8). There are several observations in western Texas reporting overcast skies (filled circles) and blowing dust (\$). Note the observations over eastern New Mexico have cleared (hollow circles) with no reports of blowing dust. A sharp contrast can be seen between the widespread area of blowing dust (magenta) and the thicker cloud cover (reds) along the edge of the frontal passage. The Dust RGB product provides the extent of dust in data-void regions of New Mexico and Texas that are cloud free and it helps the forecaster understand where dust may likely be occurring under adjacent cloud features.

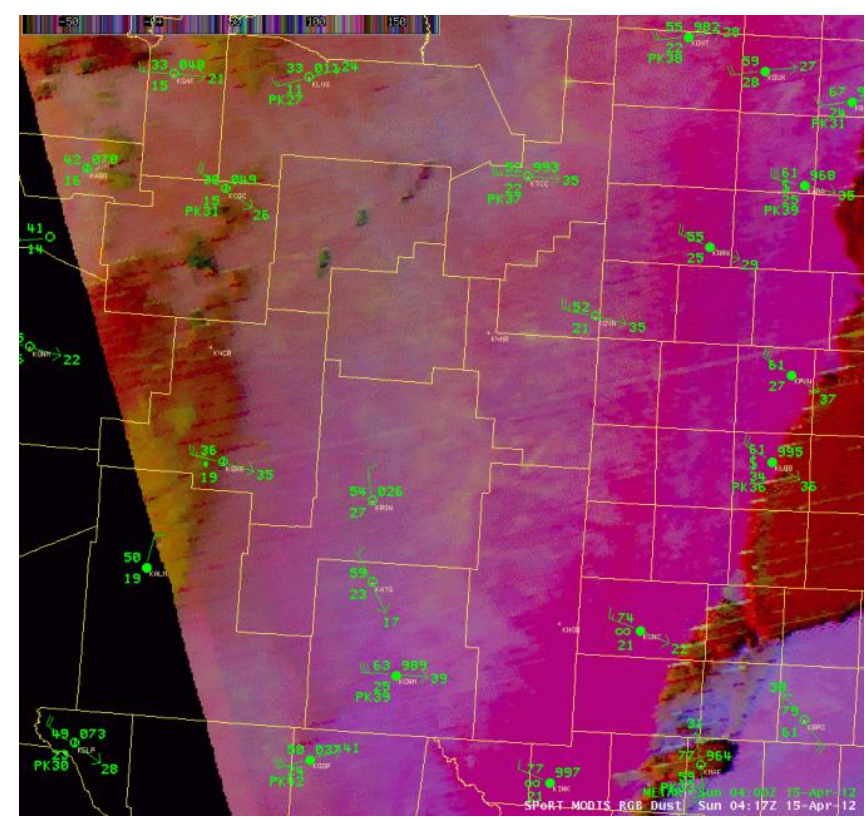

Figure 8. MODIS Dust RGB product valid 0417 UTC 15 April 2012. Observations (green) in western Texas report overcast skies (filled circles) and blowing dust (\$).

Forecasters utilizing the RGB imagery in this case had opportunities to improve timing of the onset, dura- tion, and termination of blowing dust at aviation terminals, even during the overnight. The spatial coverage of blowing dust in this case was a result of the synoptic-scale activation of upwind source regions. In this example there was the potential to increase the forecast lead time for visibility and/or ceiling restrictions that impacted KROW based on the availability of the 2033 UTC MODIS Dust RGB product. The upstream observations used in combination with the Dust RGB product and the prognosis of the frontal boundary position could have provided the opportunity for a forecast amendment to the 1800 UTC KROW TAF following the 2033 UTC MODIS Dust RGB product receipt around 2130 UTC. The potential for an amendment of the KROW 1800 UTC TAF prior to the new 0000 UTC TAF may have increased lead time of deteriorating aviation conditions by as much as $3 \mathrm{~h}$.

\section{c. Dust from frontal high winds, 11 March 2014: transportation and decision support services}

NWS ABQ forecasters have experienced operational benefits of integrating these capabilities into a decision support services framework, in addition to the impacts to aviation products and services described previously. A storm departing to the east into the Great Plains late on 10 March 2014 forced a cold front southward across eastern New Mexico through 11 March 2014. High wind warnings were in effect over much of northeastern New Mexico with the expectation that blowing dust could reduce visibilities to as low as $1.6 \mathrm{~km}(1 \mathrm{mi})$ - similar to two prior events during March 2014. As with other recent events, forecasters added blowing dust to the weather grid element of the NDFD to provide enhanced awareness to the public. A GOES visible image at 1630 UTC (Fig. 9) indicated several dust plumes developing around La Junta, Colorado (KLHX), and Lamar, Colorado (KLAA). The visibility at KLAA at 1702 UTC fell to $8 \mathrm{~km}(5 \mathrm{mi})$ with a ceiling of $823 \mathrm{~m}(2700 \mathrm{ft})$. Meanwhile, the visibility at KLHX was still reported at $16 \mathrm{~km}(10 \mathrm{mi})$ with no ceiling. Shortly thereafter the KLHX visibility at 1848 UTC fell to $0.80 \mathrm{~km}(0.5 \mathrm{mi})$ with a ceiling of $732 \mathrm{~m}(2400 \mathrm{ft})$, and the KLAA conditions deteriorated to $6.4 \mathrm{~km} \mathrm{(4} \mathrm{mi)} \mathrm{and} 762 \mathrm{~m}$ $(2500 \mathrm{ft})$ at 1853 UTC. A MODIS Dust RGB product valid at 1801 UTC (Fig. 10), arriving at approximately 1900 UTC, more clearly identified blowing dust and its spatial extent than the GOES visible channel. The Dust RGB imagery confirmed the cause of low visibility and ceiling observations over southeastern Colora- 


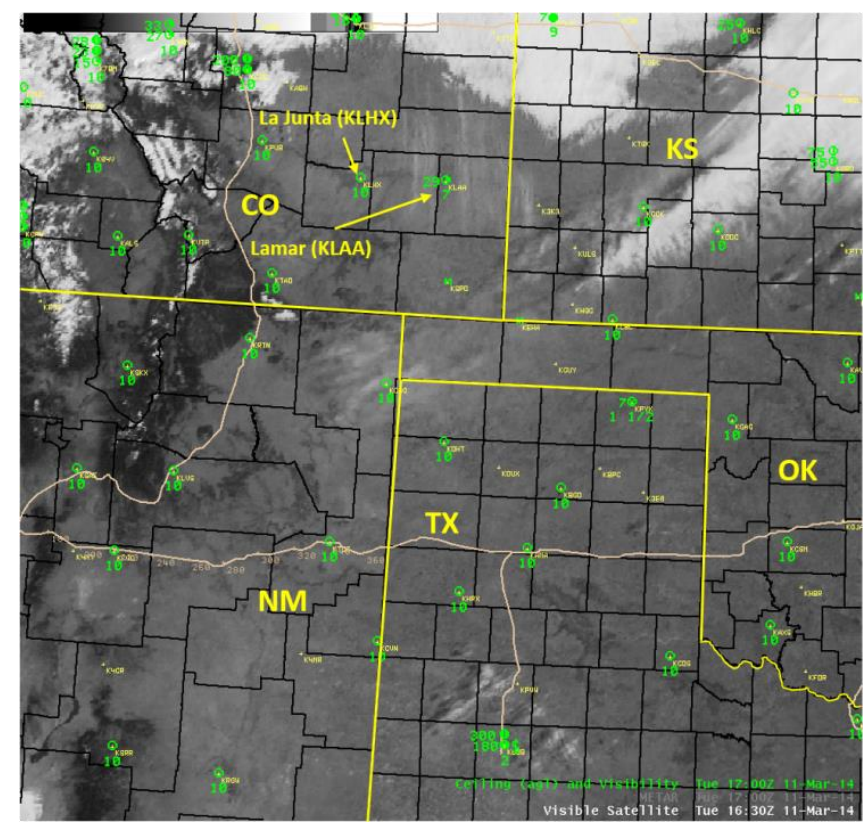

Figure 9. GOES visible image valid at 1630 UTC 11 March 2014 with aviation station plots overlaid. Station plots show visibility (mi, below station location), cloud cover (fraction, circle), and ceiling (hundreds of $\mathrm{ft}$, left of station location). Multiply mi by 1.61 for $\mathrm{km}$; multiply ft by 0.305 for $\mathrm{m}$.

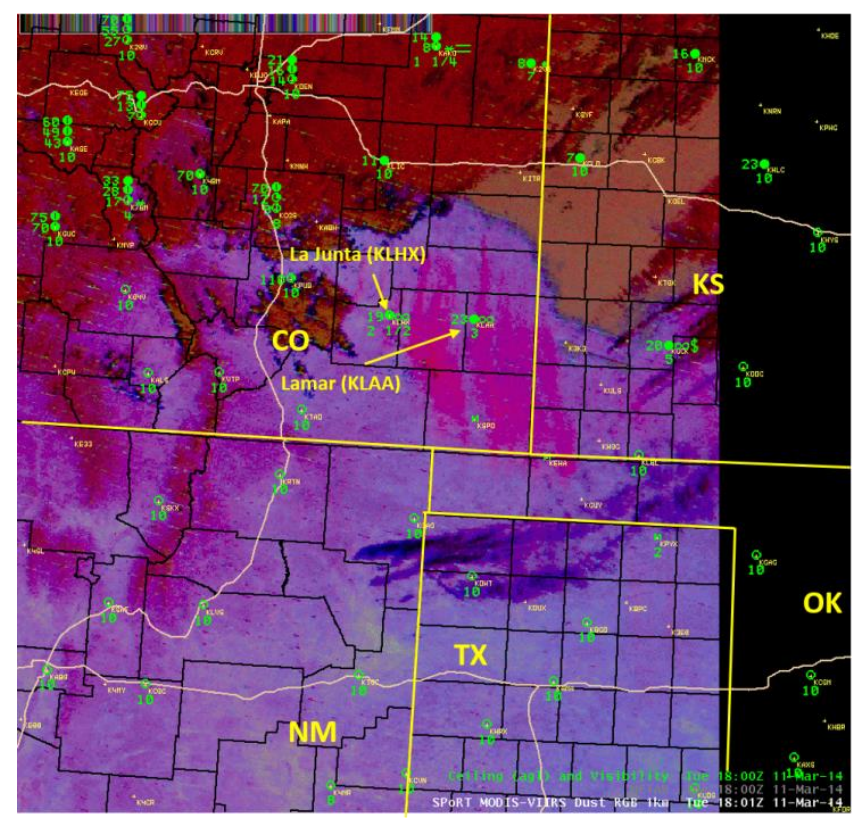

Figure 10. Dust RGB product valid 1801 UTC 11 March 2014 with aviation station plots overlaid. Station plots as in Fig. 9.

do as dust versus low clouds associated with the approaching front. In addition, the Dust RGB product efficiently differentiated the dust (magenta) from other optically thin, midlevel clouds (dark purple), which could be mistaken for dust in the GOES visible image given the similar reflectance and texture. Thereafter, the forecaster was able to evaluate visibility and ceiling characteristics of the approaching dust based on integration of the upstream observations with the Dust RGB imagery.

The subsequent Dust RGB product valid at 1941 UTC (Fig. 11), arriving near 2025 UTC, showed the area of blowing dust continuing southward into extreme northeastern New Mexico. Forecaster confidence continued to increase that, in fact, a significant area of blowing dust with visibilities near or below 1.6 $\mathrm{km}$ (1 mi) was moving into eastern New Mexico, as anticipated in the high wind warning. Shortly after the receipt of the 1941 UTC Dust RGB image, the 2033 UTC observation at Clayton, New Mexico (KCAO), indicated visibility restrictions and lowering ceilings encroaching on the area. The final Dust RGB product valid at 2019 UTC, arriving near 2100 UTC, verified the leading edge of the dust arriving at KCAO. The temporal frequency of the MODIS-VIIRS imagery in this case allowed forecasters to use a distance-speed bearing tool available in AWIPS to estimate the timing of blowing dust impacts farther south toward the Interstate-40 corridor. Note that the nearest Doppler radar data available at the lowest elevation angle around KCAO is roughly $4267 \mathrm{~m}$ (14 $000 \mathrm{ft})$ AGL. Therefore, near-surface radar coverage is limited and timing of dust impacts to I-40 could not be determined based on radar reflectivity features. The 2019 UTC overpass was the last Dust RGB imagery to arrive for this case, and forecasters transitioned to limited surface observations around the region and GOES visible imagery for the remaining analysis of the blowing dust. Nonetheless, forecasters elevated the awareness of the dust approaching the I-40 corridor by providing a Graphicast using the 2019 UTC Dust RGB product (Fig. 12). The Graphicast was posted to the NWS ABQ website close to $2100 \mathrm{UTC}$, thus providing as much as $3 \mathrm{~h}$ lead time prior to expected impacts along the I-40 corridor. The briefing was not only used to enhance public awareness of the blowing dust, but also to provide additional application-oriented examples of the Dust RGB product to NWS ABQ users.

In addition to the issuance of a Graphicast showing the blowing dust moving into the I-40 corridor, forecasters took the opportunity to initiate the teleconference briefing to the New Mexico Department of Transportation (NMDOT) Traffic Management Center (TMC). Because impacts to the I-40 corridor had not been expected for several hours at the time of the 2100 UTC Graphicast, forecasters did not provide decision support until seeking further confirmation on the 


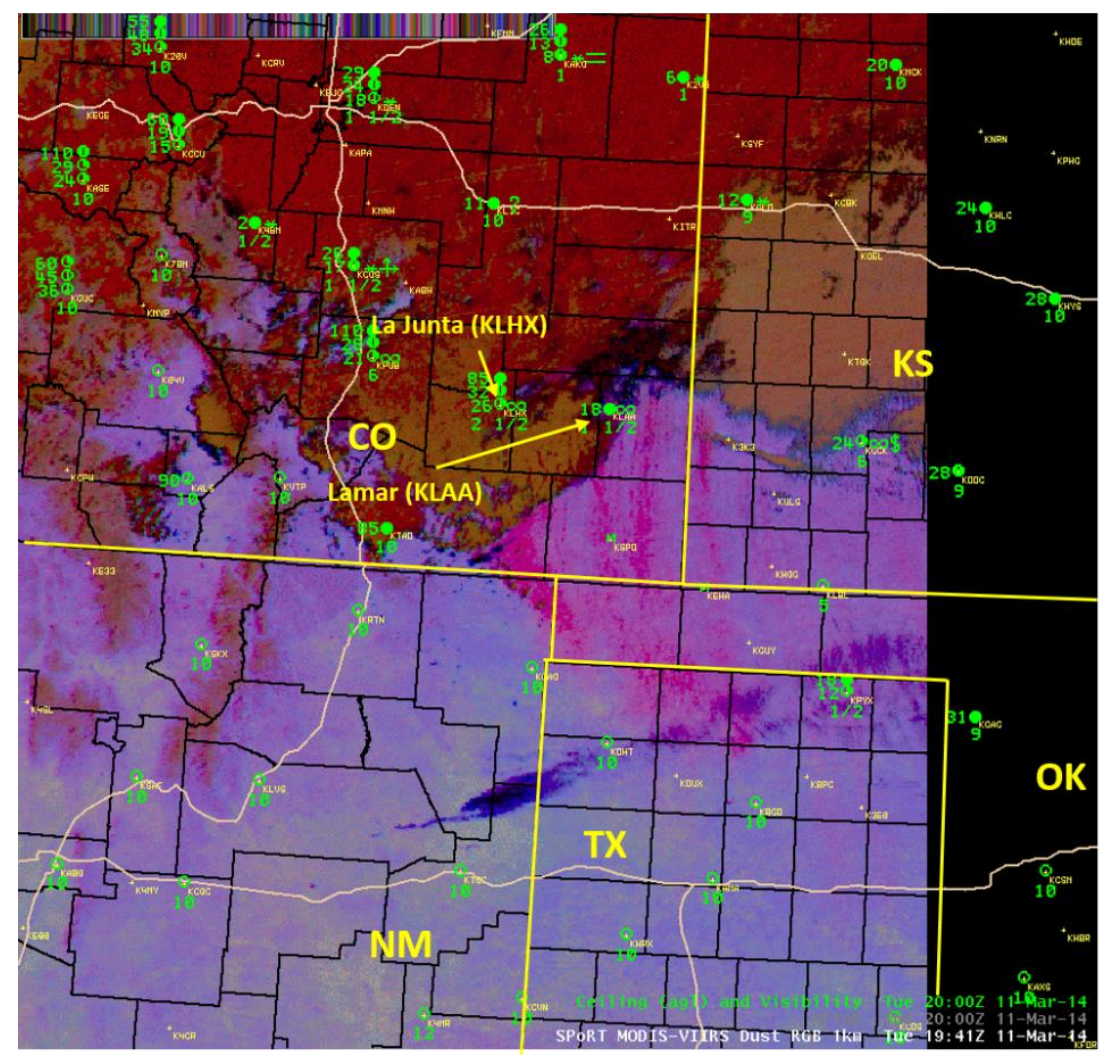

Figure 11. As in Fig. 10 but valid at 1941 UTC 11 March 2014.

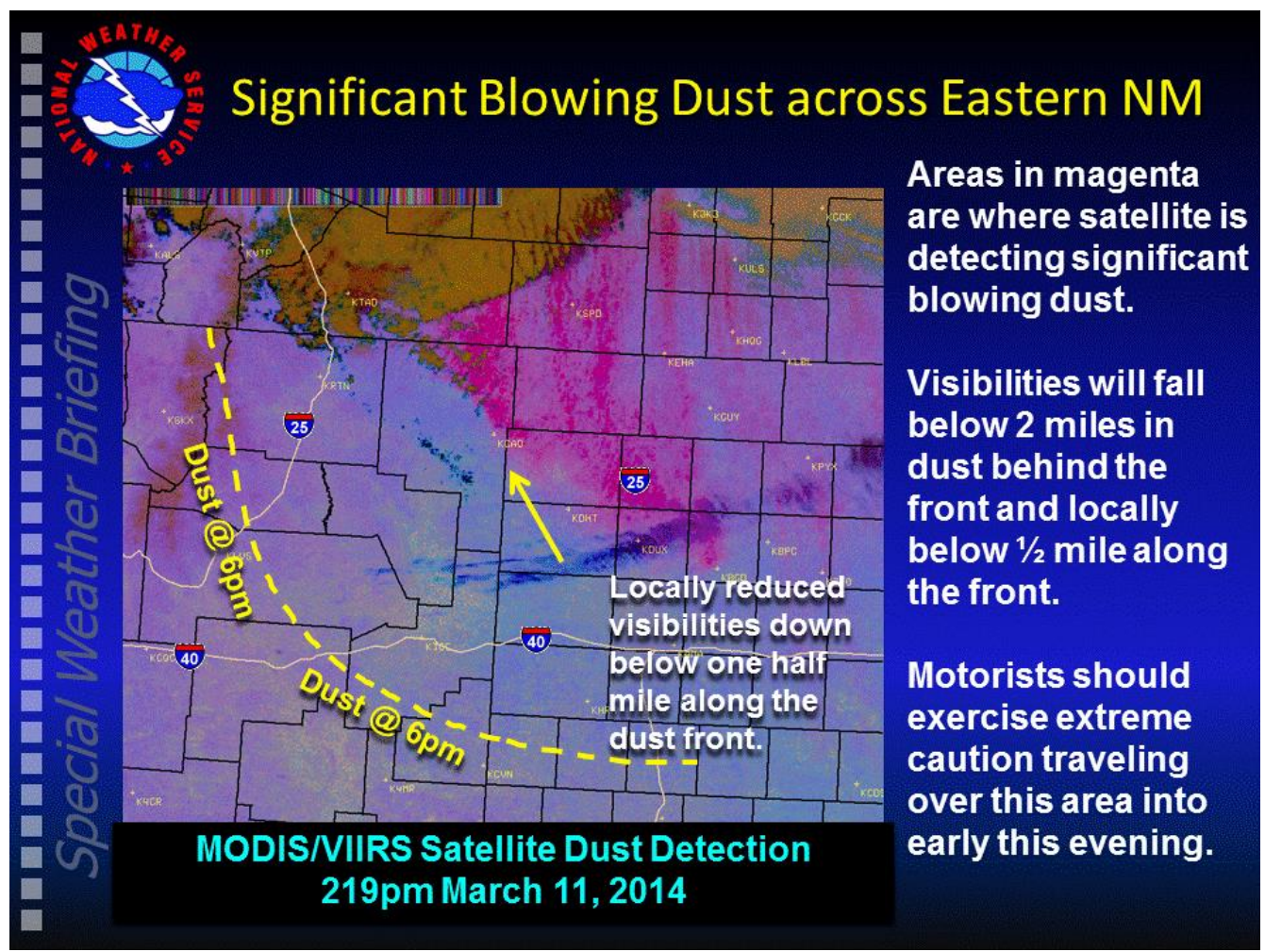

Figure 12. NWS ABQ Graphicast issued at 1500 local time on 11 March 2014. The dashed yellow line illustrates where the leading edge of the dust plume is forecast to be at 1800. MODIS/VIIRS image is valid at 1419 local time. 
evolution of the blowing dust impacts to surface visibility. The 2258 UTC observation at KTCC indicated visibilities deteriorated to $2.4 \mathrm{~km}(1.5 \mathrm{mi})$ then at 2302 UTC the visibility dropped even further to $1.2 \mathrm{~km}$ (0.75 mi). The reduced visibilities persisted at or below $1.6 \mathrm{~km}(1 \mathrm{mi})$ through $2353 \mathrm{UTC}$. The NMDOT TMC was briefed at 0015 UTC that an area of significant blowing dust moving down the plains would continue impacting areas along and west of KTCC for several hours. The TMC was able to forewarn the public of hazardous travel impacts via Dynamic Message Signs (DMS) positioned strategically across the highway system, including the area west of Tucumcari, in response to a request from NWS ABQ that the NMDOT warn motorists of blowing dust with visibilities below $1.6 \mathrm{~km}(1 \mathrm{mi})$. The NMDOT web page also was updated to include mention of blowing dust along I-40 as well as for other state highways in the area of the dust event (Fig. 13). This was the first documented, near-real-time decision support activity aimed at communicating impacts of a hazardous blowing dust event approaching a United States interstate corridor within the NWS ABQ forecast area. Despite little to no leadtime for activation of the DMS across portions of the interstate corridor, the graphical briefing using the 2019 UTC Dust RGB image projected the impacts with 2-3 h of lead time. The availability of the Dust RGB product in this example heightened forecaster awareness of the spatial extent and evolution of the blowing dust, provided greater exposure of the capabilities of the product to NWS users, and demonstrated opportunities for improving decision support that will be able to translate into potential life-saving information to the public. In hindsight, given the NWS ABQ evolving relationship with NMDOT and the introduction of new technologies including the installation of DMS sites along highways, a briefing call several hours earlier would have been more appropriate and can be considered a lesson learned.

\section{d. Operational changes at NWS ABQ encouraged by Dust RGB product}

Although proactive coordination efforts were exercised by NWS ABQ forecasters in these and many other dust case examples, in large part due to the availability of the Dust RGB product, an operational forecast change was deemed necessary in order to more effectively communicate the threats associated with blowing dust events. The NWS non-precipitation weather product specification instructions (NWS 2015a) provide guidelines for the issuance of dust storm warnings and blowing dust advisories when specified weather criteria are expected. The criteria for a blowing dust advisory are widespread or localized blowing dust reducing visibilities to $\leq 1.6 \mathrm{~km}$ (1 mi), but $>0.4 \mathrm{~km}(0.25 \mathrm{mi})$. The criteria for a dust storm warning is widespread or localized blowing dust reducing visibilities $\leq 0.4 \mathrm{~km}(0.25 \mathrm{mi})$. Prior to 2014 , NWS ABQ had never issued these hazard products for blowing dust as specified criteria had been not readily observed and there was no viable method for detection across data-void regions. In addition, blowing dust impacts prior to 2014 were relayed as complementary information in high wind warnings and wind advisories (NWS 2015a). The increasing frequency and intensity of dust events across New Mexico in 20122014 and the need to mature the weather-readiness of communities through a decision support network provided the impetus for operational change. The additional availability of the Dust RGB product provided forecasters the opportunity to present this information to the public in unique ways, enhance the forecaster's situational awareness during significant dust events, and develop RGB imagery interpretive skills. It was deemed by NWS ABQ management staff that the Dust RGB product would serve as a viable tool (now with MODIS and VIIRS, and in the future with GOES-R) to assist forecasters in delivering the type of decision support services presented herein and to allow NWS ABQ to begin issuing specific stand-alone blowing dust advisories and dust storm warnings. NWS ABQ issued its first blowing dust advisory on 30 March 2014 and then another on 27 April 2014. They also issued their first dust storm warning on 29 April 2014. A notable benefit to issuing a dust storm warning is that the product is disseminated on the Wireless Emergency Alert system. Figure 14 shows an example of a dust Storm warning alert on a typical smartphone display. The availability of the Dust RGB product and these newly developed skills serve as validation for the issuance and verification of blowing dust advisories and dust storm warnings at NWS ABQ.

\section{Summary}

Dust plumes have been traditionally difficult to analyze operationally in large part because only the large, dense dust plumes are easily seen with GOES infrared channels and visible imagery is not available at night. These factors, combined with relatively sparse in-situ observations in the western United 


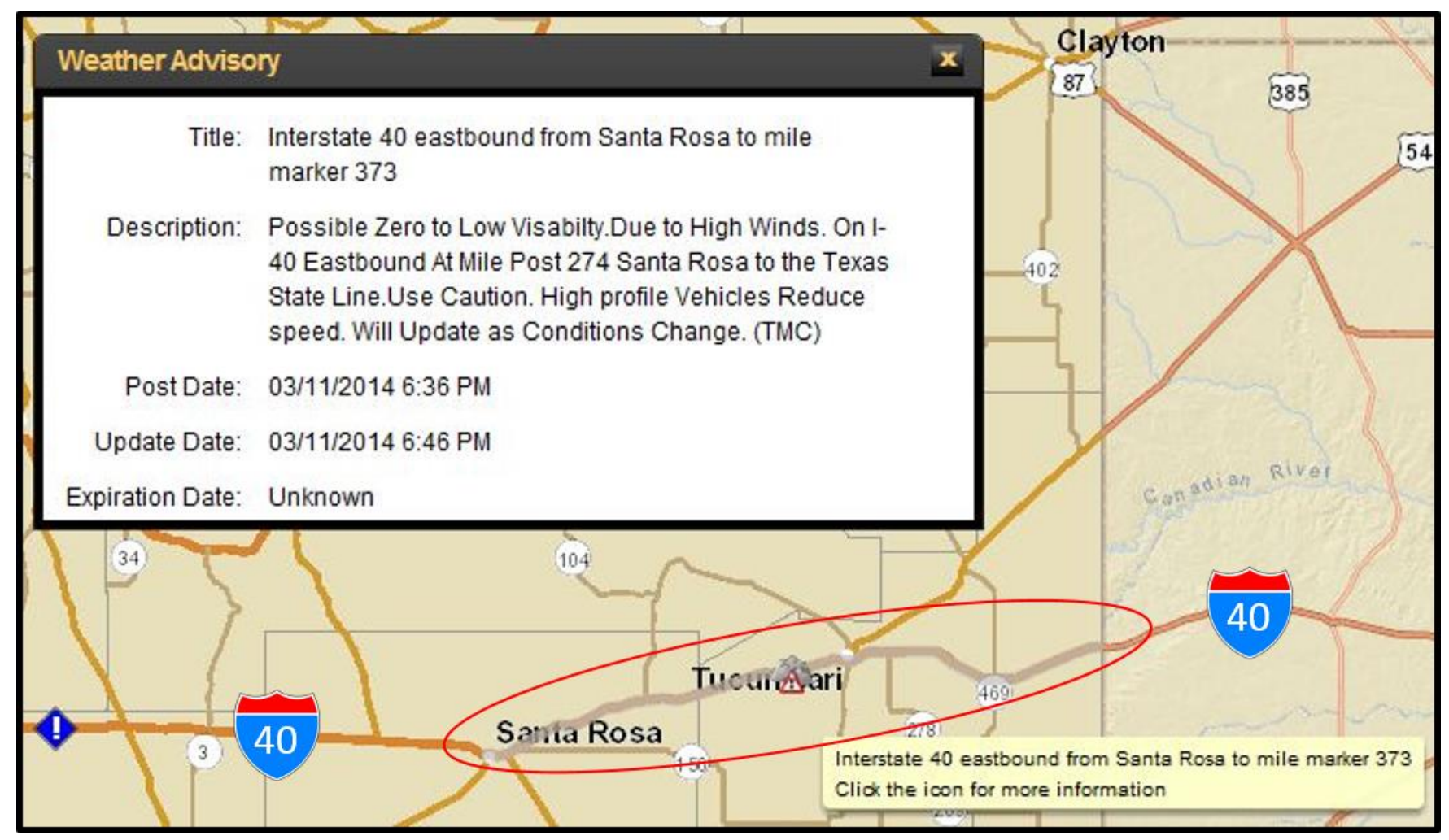

Figure 13. A weather advisory issued by the NMDOT via their website for travelers on the I-40 corridor (I-40 symbols and red oval added for emphasis) based on collaborative information provided by NWS ABQ.

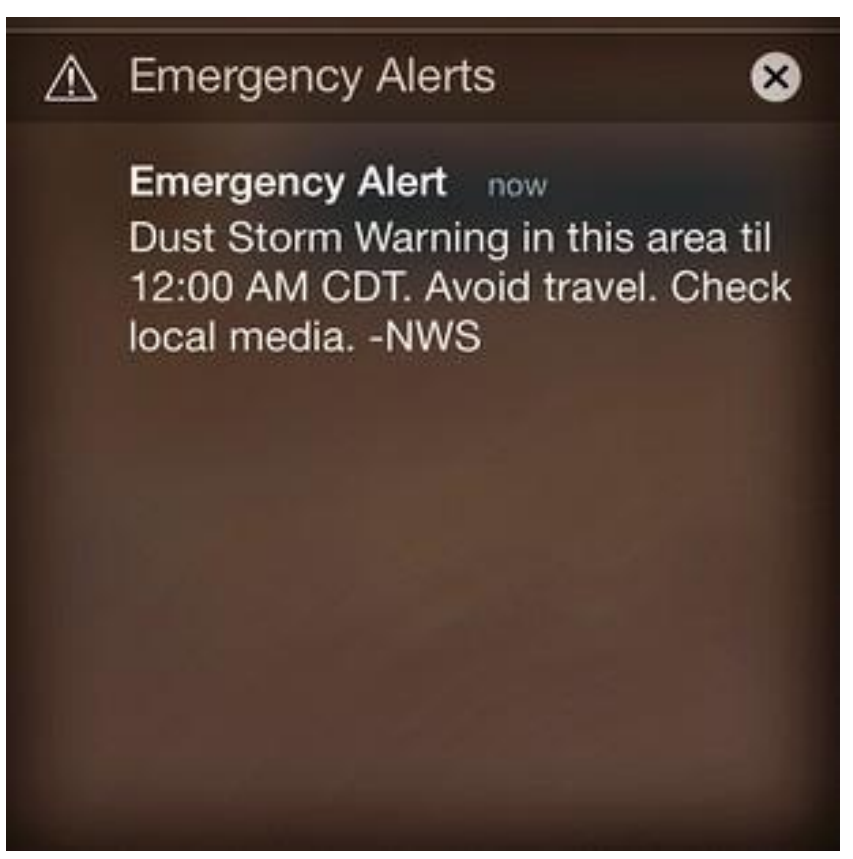

Figure 14. A Wireless Emergency Alert example for a dust storm warning on a typical smartphone display.

States, often mean that large geographical areas are included in short-term forecasts or special weather statements regarding blowing dust when only small areas are actually affected. The operational weather forecaster has had a lack of tools for the monitoring of small dust plume events and any dust events occurring at night. Even high-resolution True Color imagery from MODIS and VIIRS can be problematic as the color of the barren ground is similar to the color of blowing dust and obscures its view.

The multi-spectral Dust RGB product derived from EUMETSAT's and MSG/SEVIRI "best practices" has had significant operational value over the southwestern CONUS when applied using MODIS and VIIRS polar-orbiting instruments. The experience of supplementing standard products in operations with the new Dust RGB product has led to a better understanding and analysis of small-scale dust events that can impact TAF sites, as demonstrated in the Farmington, New Mexico, case. Further impact to TAFs via the Dust RGB product has been seen via monitoring of dust plume progression from daytime into nighttime, and increased efficiency of the RGB false coloring to differentiate dust from various cloud types, as demonstrated in the 14 April 2012 large-scale event. Application of the RGB Dust product by NWS ABQ over time has resulted in policy changes to allow blowing dust to impact ceiling conditions with their TAF product. In 
addition, the use of the Dust RGB product improved decision Support services to state officials charged with public protection by allowing forecasters to provide specific information to officials who were able to forewarn the driving public using roadway message signs. Whereas present operational value is evident, the Dust RGB product also serves as a proxy to the $\mathrm{ABI}$ instrument scheduled to be available with GOES$R$ in 2017; therefore, the RGB imagery from MODIS and VIIRS acts as a training aid for the future GOES-R capabilities, even with reduced frequency of product availability. The Dust RGB product has increased forecaster confidence in the analysis of both the areal extent and density of blowing dust, and hence, has paved the way for direct impacts to NWS ABQ warning and advisory products. Forecasters now issue stand-alone blowing dust advisories and more critical dust storm warnings for the general public. Forecasters have been able to apply the Dust RGB product in order to more accurately determine the source regions of blowing dust and therefore limit the forecasted areas to be impacted. NWS ABQ also has chosen to post the Dust RGB product on their public web page as an annotated Graphicast and received positive feedback from their end users.

The transition of the Dust RGB product to NWS $A B Q$ has proven that valuable information is provided to operational forecasters and a wider audience of users should be made aware of the utility of the Dust RGB product. Collaborations between NASA SPoRT and WFO ABQ have collected many Dust RGB imagery application examples in addition to those presented here. These and future cases where the Dust RGB product provides value are planned for use in an online library structure developed for RGB imagery training to the greater operational community. The cases presented here demonstrate the use of the Dust RGB product to anticipate travel impacts, and future areas of potential application include public health or air quality advisories related to respiratory effects for those who may be outdoors for work or recreation at the time of the blowing dust. The new paradigm of multi-spectral, geostationary imagery is near for United States-based forecasters given the upcoming launch of $G O E S-R$, and transition activities like these within the Satellite Proving Ground are preparing users to maximize their utility of new technology.

Acknowledgments. The authors thank the GOES-R and JPSS Programs for their support of the work done to produce this publication. In particular, thanks goes to the
GOES-R Visiting Scientist Program for providing funds to allow face-to-face collaborations on the application of the Dust RGB product. In addition, we recognize and appreciate the improvements made via the many insightful comments and suggestions by three anonymous reviewers.

\section{REFERENCES}

Ackerman, S. A., 1989: Using the radiative temperature difference at 3.7 and $11 \mu \mathrm{m}$ to track dust outbreaks. Remote Sens. Environ., 27, 129-133, CrossRef. , 1997: Remote sensing aerosols using satellite infrared observations. J. Geophys. Res., 102, 17069-17079, CrossRef.

Ellrod, G. P., 1995: Advances in the detection and analysis of fog at night using GOES multispectral infrared imagery. Wea. Forecasting, 10, 606-619, CrossRef.

Elmer, N. J., 2015: Limb correction of individual infrared channels for the improved interpretation of RGB composites. M.S. thesis, Dept. of Atmospheric Science, University of Alabama in Huntsville, 75 pp.

EUMETSAT, 2009: Best practices for RGB compositing of multi-spectral imagery. User Service Division, $8 \mathrm{pp}$. [Available online at oiswww.eumetsat.int/ idds/html/ doc/best_practices.pdf.]

Eyre, J. R., J. L. Brownscombe, and R. J. Allam, 1984: Detection of fog at night using Advanced Very High Resolution Radiometer (AVHRR) imagery. Meteor. Mag., 113, 266-271. [Available online at cat.inist.fr/ ?aModele $=$ afficheN\&cpsidt $=8937699$.]

Glahn, H. R., and D. P. Ruth, 2003: The new digital forecast database of the national weather service. Bull. Amer. Meteor. Soc., 84, 195-201, CrossRef.

Goldberg, M. D., D. S. Crosby, and L. Zhou, 2001: The limb adjustment of AMSU-A observations: Methodology and validation. J. Appl. Meteor., 40, 70-83, CrossRef.

, H. Kilcoyne, H. Cikanek, and A. Mehta, 2013: Joint Polar Satellite System: The United States next generation civilian polar-orbiting environmental satellite system. J. Geophys. Res., 118, 13463-13475, CrossRef.

Goodman, S. J., and Coauthors, 2012: The GOES-R Proving Ground: Accelerating user readiness for the nextgener-ation geostationary environmental satellite system. Bull. Amer. Meteor. Soc., 93, 1029-1040, CrossRef.

Hillger, D., and Coauthors, 2013: First-light imagery from Suomi NPP VIIRS. Bull. Amer. Meteor. Soc., 94, 10191029, CrossRef.

Jedlovec, G., 2013: Transitioning research satellite data to the operational weather community: The SPoRT Paradigm [Organization Profiles]. IEEE Geosci. Remote Sens. Mag., 1, 62-66, CrossRef. 
Joyce, R., J. Janowiak, and G. Huffman, 2001: Latitudinally and seasonally dependent zenith-angle corrections for geostationary satellite IR brightness temperatures. $J$. Appl. Meteor., 40, 689-703, CrossRef.

Lee, T. F., 1989: Dust tracking using composite visible/IR images: A case study. Wea. Forecasting, 4, 258-263, CrossRef.

Lienesch, J. H., and D. Q. Wark, 1967: Infrared limb darkening of the Earth from statistical analysis of TIROS data. J. Appl. Meteor., 6, 674-682, CrossRef.

Meteorological Satellite Center, 2015: Dust RGB detection of yellow sand (Asian dust). Japan Meteorological Agency, 10 pp. [Available online at www.data.jma.go.jp/mscweb/en/VRL/VLab_RGB/mate rials/RGB-Dust-Detection_of_Yellow_Sand.pdf.]

Miller, S. D., 2003: A consolidated technique for enhancing desert dust storms with MODIS. Geophys. Res. Lett., 30, 2071, CrossRef.

Moreira, N., 2011: Dust detection: The dust RGB product. EUMETSAT online Train. Libr. [Available online at www.eumetsat.int/website/home/Data/Training/Trainin gLibrary/DAT_2042669.html?lang=EN.]
NWS, cited 2015a. National Weather Service instruction 10515: WFO non-precipitation weather products specification. [Available online at www.nws.noaa.gov/ directives/sym/pd01005015curr.pdf.]

NWS, cited 2015b. National Weather Service instruction 10-813: Terminal Aerodrome Forecasts. [Available online at www.nws.noaa.gov/directives/sym/pd01008 013curr.pdf.]

Ogawa, K., and T. Schmugge, 2004: Mapping surface broadband emissivity of the Sahara Desert using ASTER and MODIS data. Earth Interact., 8, 1-14, CrossRef.

Schipper, J., and V. Nietosvaara, 2009: Operational use of RGBs. EUMETrain. [Available online at www.eumetrain.org/resources/operational_use_rgb.html.]

Schmit, T. J., M. M. Gunshor, W. P. Menzel, J. J. Gurka, J. $\mathrm{Li}$, and A. S. Bachmeier, 2005: Introducing the nextgeneration Advanced Baseline Imager on GOES-R. Bull. Amer. Meteor. Soc., 86, 1079-1096, CrossRef.

Zavodsky, B. T., A. L. Molthan, and M. J. Folmer, 2013: Multispectral imagery for detecting stratospheric air intrusions associated with mid-latitude cyclones. $J$. Oper. Meteor., 1, 71-83, CrossRef. 